\title{
The source detection of 28 September 2018 Sulawesi tsunami by using ionospheric GNSS total electron content disturbance
}

\author{
Jann-Yenq Liu ${ }^{1,2,3^{*}} \mathbb{\mathbb { D }}$, Chi-Yen Lin ${ }^{1,2}$, Yuh-Ing Chen ${ }^{4}$, Tso-Ren Wu ${ }^{5}$, Meng-Ju Chung ${ }^{5}$, Tien-Chi Liu ${ }^{5}$, Yu-Lin Tsai ${ }^{5}$, \\ Loren C. Chang ${ }^{1,2}$, Chi-Kuang Chao ${ }^{1,2}$, Dimitar Ouzounov ${ }^{6}$ and Katsumi Hattori ${ }^{7}$
}

\begin{abstract}
The 28 September 2018 magnitude Mw7.8 Palu, Indonesia earthquake $\left(0.178^{\circ} \mathrm{S}, 119.840^{\circ} \mathrm{E}\right.$, depth $\left.13 \mathrm{~km}\right)$ occurred at 10:02 UTC. The major earthquake triggered catastrophic liquefaction, landslides, and a near-field tsunami. The ionospheric total electron content (TEC) derived from records of 5 ground-based global navigation satellite system (GNSS) receivers is employed to detect tsunami traveling ionospheric disturbances (TTIDs). In total, 15 TTIDs have been detected. The ray-tracing and beamforming techniques are then used to find the TTID source location. The bootstrap method is applied in order to further explore the possible location of the tsunami source based on results of the two techniques, which show the beamforming technique has a slightly better performance on finding possible locations of the tsunami source. Meanwhile, the circle method is employed to examine tsunami signatures of the sea-surface height and video records, and find possible tsunami origin locations. The coincidence of the TTID source location and the tsunami location shows that the ionospheric TEC recorded by local ground-based GNSS receivers can be used to confirm the tsunami occurrence, find the tsunami location, and support the tsunami early warning.
\end{abstract}

Keywords: Sulawesi tsunami, GNSS TEC, Beamforming, Ray-tracing, Bootstrap method

\section{Introduction}

Seismic waves and tsunami of a large earthquake can significantly induce traveling atmospheric disturbances (TADs) near the Earth's surface in the epicenter and the tsunami source areas (Liu et al. 2011). These TADs propagate vertically at the local sound speed traveling from the atmosphere into the ionosphere, forming traveling ionospheric disturbances (TIDs) and simultaneously inducing internal gravity waves within. Liu et al. (2019a) examined ionospheric electron density profiles away from the epicenter and the tsunami source areas during the 2011 M9.0 Tohoku earthquake, and found that underneath Rayleigh and tsunami waves

\footnotetext{
*Correspondence: tigerjyliu@gmail.com

${ }^{1}$ Center for Astronautical Physics and Engineering, National Central University, Taoyuan, Taiwan

Full list of author information is available at the end of the article
}

can induce more prominent TIDs. Data recorded from ground-based global navigation satellite system (GNSS) receivers have been used to observe ionospheric total electron content (TEC) disturbances triggered by seismic waves (Jung et al. 2006; Liu et al. 2010, 2011, 2012, 2016; Sun et al. 2016; Tsai et al. 2011) and tsunami waves (Artru et al. 2005; Liu et al. 2006a, b, 2011, 2019a; Tsai et al. 2011; Galvan et al. 2011; Kamogawa et al. 2016; Komjathy et al. 2012). Since the horizontal speed of seismic waves of $2.5-3.5 \mathrm{~km} / \mathrm{s}$ very differs from that of tsunami waves of $200-250 \mathrm{~m} / \mathrm{s}$, we can clearly identify and easily separate tsunami-induced and earthquake-induced TEC disturbances. Liu et al. (2006a) employ the ray-tracing technique (Aki and Richards 2002) to estimate the arrival times at locations of tsunami traveling ionospheric disturbances (TTIDs) of TEC for finding the tsunami source, as well as to see whether the observed disturbances of the ionospheric 
GNSS TEC is triggered by the tsunami or not during the 26 December 2004 M9.3 Sumatra earthquake (Liu et al. 2006a). They reported that the source of the 26 December 2004 Indian Ocean tsunami was about $580 \mathrm{~km}$ southwest from the Sumatra epicenter. Recently, Savastano et al. (2017) showed the possibility of detecting TTIDs in a real-time scenario. Liu et al. (2019a) applied the ray-tracing technique (Lee and Stewart 1981), and the beamforming technique (Huang et al. 1999) to analyze ionospheric TEC disturbances of the 2004 Indian Ocean tsunami, showing that the TTIDs can be rapidly identified within $20 \mathrm{~min}$ after the earthquake allowing the tsunami source to be located. They further proposed to use existing ground-based GNSS (including GPS, GLONASS, Galileo, and BeiDou) receiving stations, which have been routinely operated by International GNSS Service (IGS), to monitor TTIDs in real time for tsunami early warning applications.

On 28 September 2018, a Mw 7.8 earthquake occurred at 10:02:44 $\mathrm{UT}$ at $0.18^{\circ} \mathrm{S}, 119.84^{\circ} \mathrm{E}$ in the mountainous Donggala Regency, Central Sulawesi, and generated a tsunami (http://itic.ioc-unesco.org/index.php). International Tsunami Information Center reported that $5 \mathrm{~min}$ after the earthquake, the Indonesia Agency for Meteorology, Climatology and Geophysics (Badan Meteorologi Klimatologi dan Geofisika-BMKG) issued a tsunami warning for a local tsunami. Recently, a retrieved marigram from the Pantoloan-Sulteng tide gauge $\left(0.695^{\circ} \mathrm{S}\right.$, $\left.119.827^{\circ} \mathrm{E}\right)$ shows a $3.8-\mathrm{m}$ trough-to-peak tsunami that arrived $6 \mathrm{~min}$ after the earthquake occurrence. There were no other nearby instrumental observations. Several analyses based on pictures, post-disaster information, and video clips suggest the first tsunami wave hit the Palu beach area $\left(0.885^{\circ} \mathrm{S}, 119.857^{\circ} \mathrm{E}\right) 7-12 \mathrm{~min}$ after the earthquake (Heidarzadeh et al. 2019). Preliminary field surveys conducted by the BMKG and IRIDeS/Indonesia Ministry of Environment and Forestry/Chuo University report an eyewitness height of up to $11.3 \mathrm{~m}$ in Palu and 3-10 $\mathrm{m}$ on the west and east sides of the bay. Detailed field surveys can be found in Omira et al. (2019). However, based on the above information, it is still difficult to locate the tsunami's source.

In this paper, the time delay method, the circle method, the ray-tracing technique, and the beamforming technique are employed. Figure 1 illustrates locations of the Sulawesi epicenter and 15 TTID signatures identified from TEC measurements of 5 ground-based GNSS receiving stations. The time delay method is applied on distances and arrival times of the TTIDs to estimate the associated horizontal speed and onset time, which are further given, respectively, to the ray-tracing technique and the beamforming technique to locate the tsunami's source area. A statistical bootstrap analysis is also conducted to evaluate the reliability of the computed tsunami's source location.

\section{lonospheric tsunami disturbance and source location}

Tsunami waves create mechanical disturbances in the near sea-surface atmosphere, which propagate upward into the ionosphere, interact with the ionized gas within, and disturb the ionospheric plasma, electron density, TEC, etc. In general, it takes 8-10 min for disturbances activated by seismic or tsunami waves traveling from the earth's surface upward into the ionosphere at $300 \mathrm{~km}$ altitude, indicating that the TTID upward propagation speed is of about $500-625 \mathrm{~m} / \mathrm{s}$, which is near the averaged sound speeds in the atmosphere of between the ground and $300 \mathrm{~km}$ altitude (Liu et al. 2006a, b, 2011, 2016, 2019b). In this study, for simplicity, we assume the TTID average upward speed is $600 \mathrm{~m} / \mathrm{s}$.

When radio signals transmitted from GNSS satellites at about 20,200 km altitude pass through the ionosphere, and reach ground-based receivers, they will experience changes in propagation speed and refraction from the ionospheric plasma, electron density, TEC, etc. Since the largest electron density is at the F2-peak, which is usually located at about $250-350 \mathrm{~km}$ altitude, the ionosphere then can be treated as a thin shell at about 325-375 km altitude (Sardon et al. 1994; Liu et al. 1996). From recorded broadcast ephemeris and assuming the thin-shell ionosphere at $325 \mathrm{~km}$ (Davies 1990; HofmannWellenhof et al. 1992; Liu et al. 1996; Sardon et al. 1994; Wu 1992), the intersection point, which is termed the ionospheric pierce point (IPP), between the signal path from a GNSS satellite to a ground-based receiver and the thin-shell ionosphere give the longitude and latitude location of TTIDs. Thus, the TEC at the IPP acts as a space tide gauge or a space buoy floating at $325 \mathrm{~km}$ altitude to detect TTIDs.

Figure 1a displays locations of Sulawesi epicenter and the 15 TTIDs of the 5 GNSS ground-based receivers. To detect TTIDs, we first apply the time delay method (Liu et al. 2006a, 2011, 2019a; Tsai et al. 2011) to estimate the possible arrival time range of TEC fluctuations observed at each GNSS receiving station, and then identify the precise arrival time. For example, the IPP point observed kat1 21 was at $2135 \mathrm{~km}$ from epicenter, and assuming the tsunami horizontal speed of about $190-300 \mathrm{~m} / \mathrm{s}$, it requires the travel time of about $2.1(=2135 \mathrm{~km} / 300 \mathrm{~m} / \mathrm{s}+8 \mathrm{~min})$ to $3.3(=2135 \mathrm{~km} / 190 \mathrm{~m} / \mathrm{s}+8 \mathrm{~min})$ hours, where $8 \mathrm{~min}$ of the vertical travel time should be included. We further add up the travel time and the earthquake time, and search the possible arrival time range between 12.1 and 13.3 UT. The precise arrival time (12.28 UT) of TTIDs is identified, when the TEC starts drastically changing. Figure $1 \mathrm{~b}$ illustrates 15 TEC variations filtered using a 


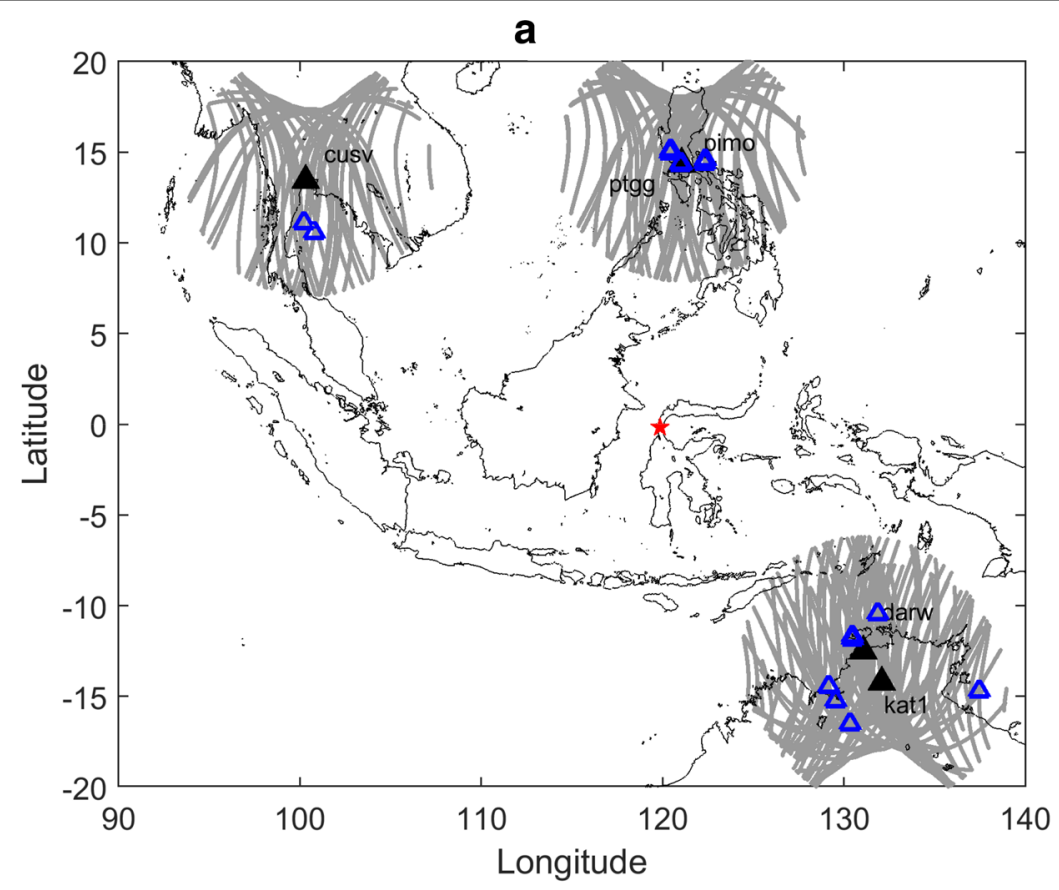

b

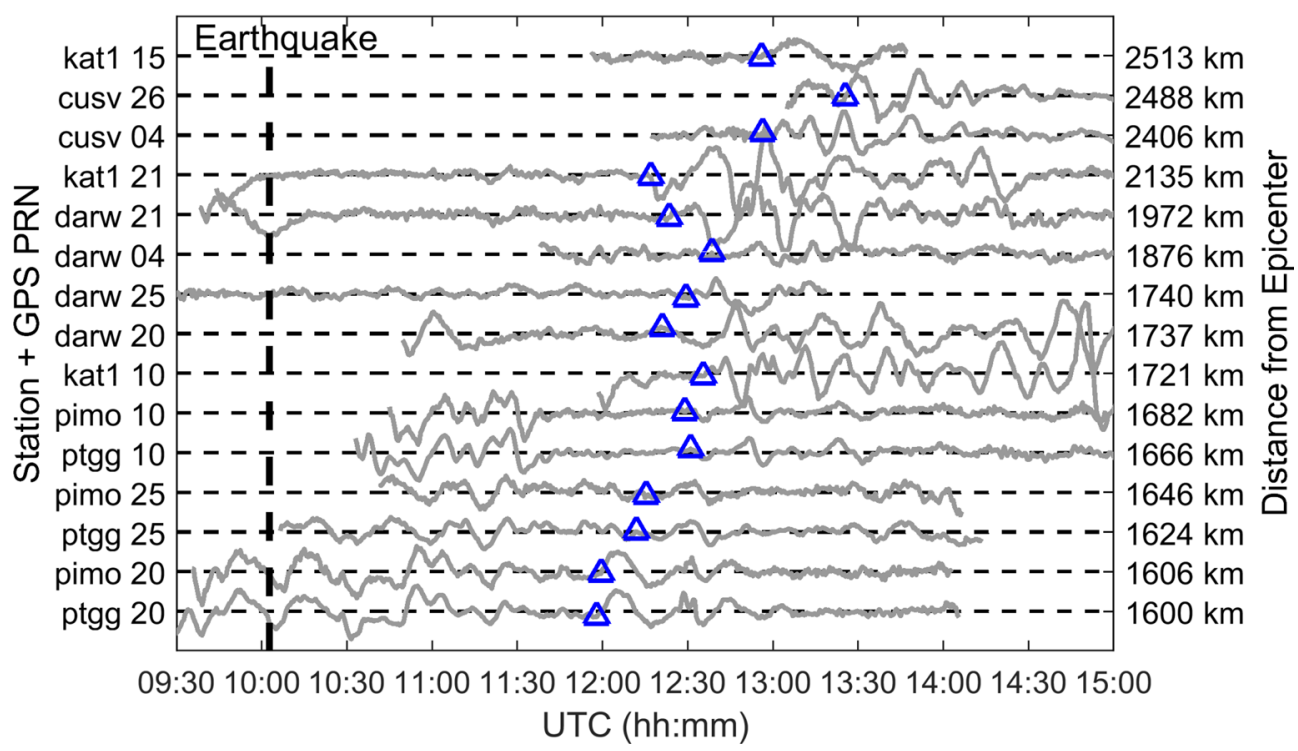

Fig. 1 The TTID signals of Sulawesi tsunami using GNSS TEC. a The locations of epicenter (red star) and GNSS receiving stations (black triangle). Blue open triangles denote the locations of TTID signals. b 15 detected TTIDs from 5 ground-based GNSS stations are shown as black lines and blue triangles represent the start time of TTIDs. Black dash line indicates the occurrence time of earthquake

high-pass filter with the 20-min cut-off period, the arrival time of each TTID, and the arrival time versus the epicenter distance (i.e., the distance between the epicenter and each observed TTID) (for detail see, Table 1). The average horizontal propagation speed of the TTIDs usually is close to that of the typical speed of tsunami waves of 200-250 m/s (Dean and Dalrymple 1984; Dias and Dutykh 2007; Murty 1977) in the open sea. A slope of the distance versus the arrival time of the 15 TTIDs shows the average horizontal speed being about $228 \mathrm{~m} / \mathrm{s}$. To further search the TTID's source location, we apply the ray-tracing technique and beamforming technique on the arrival time and the location of observed TTIDs (Table 1). 
Table 1 Locations and propagations of TTIDs

\begin{tabular}{|c|c|c|c|c|}
\hline \multirow{2}{*}{$\frac{\text { TTID }}{\text { kat1 } 15}$} & \multicolumn{2}{|c|}{ Location $\left({ }^{\circ} \mathrm{N},{ }^{\circ} \mathrm{E}\right)$} & \multirow{2}{*}{$\begin{array}{l}\text { Arrival time (UT) } \\
12.9333\end{array}$} & \multirow{2}{*}{$\begin{array}{l}\text { Distance (km) } \\
2513\end{array}$} \\
\hline & -14.72 & 137.47 & & \\
\hline cusv 26 & 11.10 & 100.27 & 13.4250 & 2488 \\
\hline cusv 04 & 10.58 & 100.80 & 12.9417 & 2406 \\
\hline kat1 21 & -16.51 & 130.35 & 12.2833 & 2135 \\
\hline darw 21 & -15.26 & 129.53 & 12.3917 & 1972 \\
\hline darw 04 & -14.46 & 129.17 & 12.6417 & 1876 \\
\hline darw 25 & -10.45 & 131.88 & 12.4917 & 1740 \\
\hline darw 20 & -11.86 & 130.47 & 12.3500 & 1737 \\
\hline kat1 10 & -11.67 & 130.46 & 12.5917 & 1721 \\
\hline pimo 10 & 15.11 & 120.46 & 12.4833 & 1682 \\
\hline ptgg 10 & 14.96 & 120.43 & 12.5167 & 1666 \\
\hline pimo 25 & 14.58 & 122.36 & 12.2583 & 1646 \\
\hline ptgg 25 & 14.38 & 122.32 & 12.2000 & 1624 \\
\hline pimo 20 & 14.38 & 121.03 & 11.9917 & 1606 \\
\hline ptgg 20 & 14.32 & 120.99 & 11.9667 & 1600 \\
\hline
\end{tabular}

The ray-tracing technique (Lee and Stewart 1981) and the beamforming technique (Huang et al. 1999) are used to globally search for the TTID's source location inside a rectangular area between $\pm 30^{\circ} \mathrm{N}$ and $70-150^{\circ} \mathrm{E}$, by shifting along a $0.1^{\circ}$ grid in the longitudinal and then latitudinal direction or vice versa. In the ray-tracing technique, for a given velocity model, we can guess a source location, and calculate the travel time from the guessed source location to each TTID, which is the distance between the guessed source location and the TTID location divided by the given velocity, including the upward speed and the horizontal speed. We then subtract the calculated travel time from the arrival time to obtain the origin time for each TTID. Since there are 15 origin times, their associated average and standard deviation at the guessed source location can be computed. We then repeat the above process by shifting the guessed source location $0.1^{\circ}$ in the longitudinal direction and then the latitudinal one to cover the entire rectangular area. Finally, we contour the standard deviations of the origin time in the rectangular area to find the location of the minimum, where can be considered as the TTID source location. Since the most prominent TTID signature generally is triggered by its underlying tsunami wave (Liu et al. 2019a), the location of the TTID source should be very close to that of the tsunami origin but the appearance time with 8-10 min delay. Assuming the thin-shell ionosphere at $325 \mathrm{~km}$ altitude, the averaged vertical speed of $600 \mathrm{~m} / \mathrm{s}$, and the horizonal speed of $228 \mathrm{~m} / \mathrm{s}$, the ray-tracing yields that the minimum of the standard deviation is $\pm 14.3 \mathrm{~min}$ with the averaged origin time of 10:02 UTC located at $0.7^{\circ} \mathrm{S}, 119.6^{\circ} \mathrm{E}$, where is $63 \mathrm{~km}$ southsouthwest of the epicenter and the most likely location of the TTID or tsunami source (Fig. 2a). In fact, various horizonal speeds of $200-250 \mathrm{~m} / \mathrm{s}$ have been tested, and the speed of $228 \mathrm{~m} / \mathrm{s}$ results in the TTID onset time of 10:02 UTC. This suggests that the ray-tracing technique is very sensitive to the velocity model.

Similarly, in the beamforming technique, for a given TTID origin time at 10:02 UTC, we can guess a source location, find the distance, and calculate the travel time, as well as compute the averaged velocity and standard deviation of the 15 TTIDs for each guessed source location. Again, we plot contours of standard deviations of the velocity in the rectangular area to find the minimum, which again can be considered as the TTID source location. Assuming the thin-shell ionosphere at the same $325 \mathrm{~km}$ altitude and an averaged vertical travel time of $542 \mathrm{~s}$ (i.e., $325 \mathrm{~km}$ divided by $600 \mathrm{~m} / \mathrm{s}$ ), the beamforming technique finds that the minimum of the standard deviation of $\pm 23.7 \mathrm{~m} / \mathrm{s}$ with the averaged horizontal speed of $227.5 \mathrm{~m} / \mathrm{s}$ is located at $0.6^{\circ} \mathrm{S}, 119.6^{\circ} \mathrm{E}$, which is about $53 \mathrm{~km}$ south-southwest of the epicenter, to be the most probable the TTID and/or tsunami source location (Fig. 2b). Note that the averaged horizontal speed of $227.5 \mathrm{~m} / \mathrm{s}$ computed by the beamforming technique is very close to that the $228 \mathrm{~m} / \mathrm{s}$ assumed by the ray-tracing technique.

\section{Statistical analyses of TTID source location}

It has been demonstrated that the possible location of the tsunami source can be found by using both the ray-tracing and beamforming techniques based on the 15 TTIDs. To further explore the possible location of the tsunami source, the bootstrap method (Efron and Tibshirani 1986 ) is used to find the confidence region of the source location centered at the original detected TTID source location. In the bootstrap method, 1000 samples of size 15 are resampled with replacement from the 15 TTIDs to obtain the associated 1000 TTID's source locations based on either the ray-tracing or beamforming technique (yellow dots in Fig. 2c, d).

Note that the bootstrap source locations show a northeast-southwest-ward trend and have different variations in longitude and latitude. The covariance matrix of the longitude and latitude of bootstrap source locations is then computed, hence the Mahalanobis distance (Dillon and Goldstein 1984) between each bootstrap source location and the original detected source location is calculated. Moreover, the Mahalanobis distances are ordered from the smallest to the largest so that the 90-percentile of the distances is obtained. The $90 \%$ confidence regions for the possible tsunami source locations detected by the ray-tracing and beamforming techniques (white ellipses in Fig. 2c, d) based on the associated 90-percentile of the 

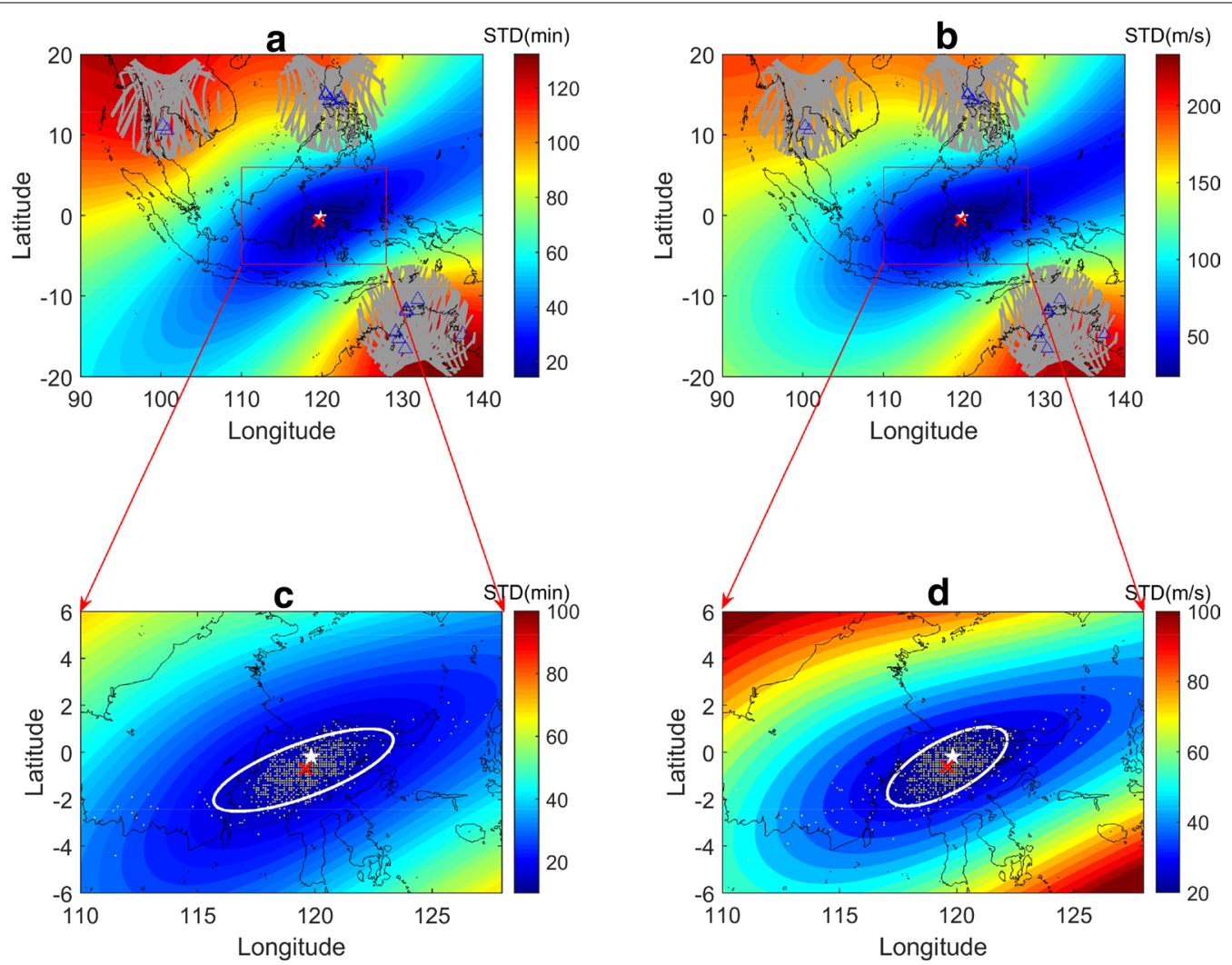

Fig. 2 Contour of STD of a travel times and $\mathbf{b}$ speeds estimated by the ray-tracing and beamforming technique, separately. The blue open triangles indicate the TTID locations. The white star indicates the epicenter reported by the USGS, and red crosses represent the estimated tsunami sources. The bootstrap tsunami sources by using ray-tracing $(\mathbf{c})$ and beamforming $(\mathbf{d})$. The yellow dots indicate the bootstrap locations of tsunami source. The white ellipses represent the $90 \%$ confidence interval for the possible tsunami source locations

distances are finally constructed which can be, respectively, expressed as:

$$
\begin{aligned}
& 0.5787(x-119.5)^{2}+2.7379(y+0.8)^{2} \\
& -1.8358(x-119.5)(y+0.8) \leq 3.9820,
\end{aligned}
$$

and

$$
\begin{aligned}
& 1.3100(x-119.6)^{2}+3.0104(y+0.6)^{2} \\
& -2.6814(x-119.6)(y+0.6) \leq 4.6647,
\end{aligned}
$$

where $x$ and $y$ denote the longitude and latitude. The $90 \%$ confidence region of the beamforming techniques is slightly more concentrated than that of the ray-tracing technique.

\section{Discussion and conclusion}

Scientists (Liu et al. 2006a, b, 2011, 2019a; Tsai et al. 2011) have found that the distance between the epicenter and the tsunami origin location can be on the order of hundreds $\mathrm{km}$. For the 2011 Tohoku tsunami, Liu et al. (2011) using dense IPPs of 12,000 space buoys and/or tide gauges directly imaged the tsunami origin location, which is $200 \mathrm{~km}$ eastward of the epicenter, while Tsai et al. (2011), assuming a horizontal speed of $210 \mathrm{~m} / \mathrm{s}$ and applying the ray-tracing technique on a limited number of 27 TTIDs, found that the tsunami origin was $195 \mathrm{~km}$ southeast of the epicenter. Thus, the discrepancy of the tsunami origin locations between the two studies might result from the limited number of 27 TTIDs being used by Tsai et al. (2011). Additionally, the ray-tracing and beamforming techniques have been employed to find the most prominent vertical surface motion caused by Rayleigh waves of earthquakes (Jung et al. 2006; Liu et al. 2010, 2012), and however, the beamforming technique has not yet been often applied on TTIDs in detail. Liu et al. (2010) found that results of the ray-tracing technique are a function of the velocity model, while the beamforming technique can successfully locate the most prominent vertical surface motion of the Chi-Chi earthquake. Note that the horizontal speed might significantly disturb the detection of the TTID source location. Several factors, such as temperatures, densities, wind speeds, etc., in the atmosphere, can easily affect TTID propagation speeds, and therefore it is difficult to issue a suitable and/ 
or correct velocity model. By contrast, the beamforming technique assumes the origin time of TTIDs near the earth's surface being close to that of the co-located tsunami waves, which is the same as the earthquake occurrence time. It might be the assumption being suitable and close to the reality, the beamforming technique can quickly locate the TTID and/or tsunami location.

Figure 2c, d reveals that the $90 \%$ confidence region of the beamforming technique is more concentrated than that of the ray-tracing one, which suggests that the beamforming technique might yield a better performance in locating the source origin of TTIDs or tsunami waves. To further find if the TTID source locations derived from the ray-tracing and beamforming techniques are close to the tsunami origin location, we apply the circle method (Lay and Wallace 1995; Liu et al. 2006b) on data of the Pantoloan-Sulteng tide gauge $\left(0.695^{\circ} \mathrm{S}, 119.827^{\circ}\right.$ E) that the tsunami arrived at $6 \mathrm{~min}$ after the earthquake occurrence, and of video records showing the time that the first tsunami wave hits the Palu beach area $\left(0.885^{\circ}\right.$ $\mathrm{S}, 119.857^{\circ} \mathrm{E}$ ), roughly 7-12 $\mathrm{min}$ after the earthquake. Assuming a tsunami wave with $80 \mathrm{~m} / \mathrm{s}$ in Palu bay (let the bay depth of about $700 \mathrm{~m}$ ), we apply the circle method on the tsunami arrival time of $6 \mathrm{~min}$ and 7-12 min after the earthquake and compute and draw two rings of possible tsunami source locations centering at Pantoloan-Sulteng tide gauge and at the Palu beach area, respectively. Figure 3 displays the ring centered at Pantoloan with radii of the inner edge of $24 \mathrm{~km}(=80 \mathrm{~m} / \mathrm{s} \times 5 \mathrm{~min})$ and the outer edge of $29 \mathrm{~km}(=80 \mathrm{~m} / \mathrm{s} \times 6 \mathrm{~min}) \mathrm{km}$, and the ring centered at the Palu beach area with radii of the inner edge of $34 \mathrm{~km}(=80 \mathrm{~m} / \mathrm{s} \times 7 \mathrm{~min})$ and the outer edge of $58 \mathrm{~km}(=80 \mathrm{~m} / \mathrm{s} \times 12 \mathrm{~min}) \mathrm{km}$. The intersection area of the two rings can be considered as the tsunami source location. Since the two TTID source locations fall inside of the intersection area, both the beamforming and raytracing techniques are suitable to find the tsunami origin location.

The source of 2018 Sulawesi tsunami is still under debate. Heidarzadeh et al. (2019) used tsunami raytracing method to find out the potential landslide locations inside the Palu Bay. Omira et al. (2019) identified locations of the coastal landslides by combing the data of video analysis, field survey, and satellite images. Song et al. (2019) proposed a two-segment fault model by using geodetic data. By contrast, our results of the ray-tracing technique, the beamforming technique, and the circle method show that the possible tsunami source locations are near but just outside the Palu Bay. The discrepancy might result from the fact that the limited number of the 15 TTIDs and that the used ground-based GNSS receivers are too far away from

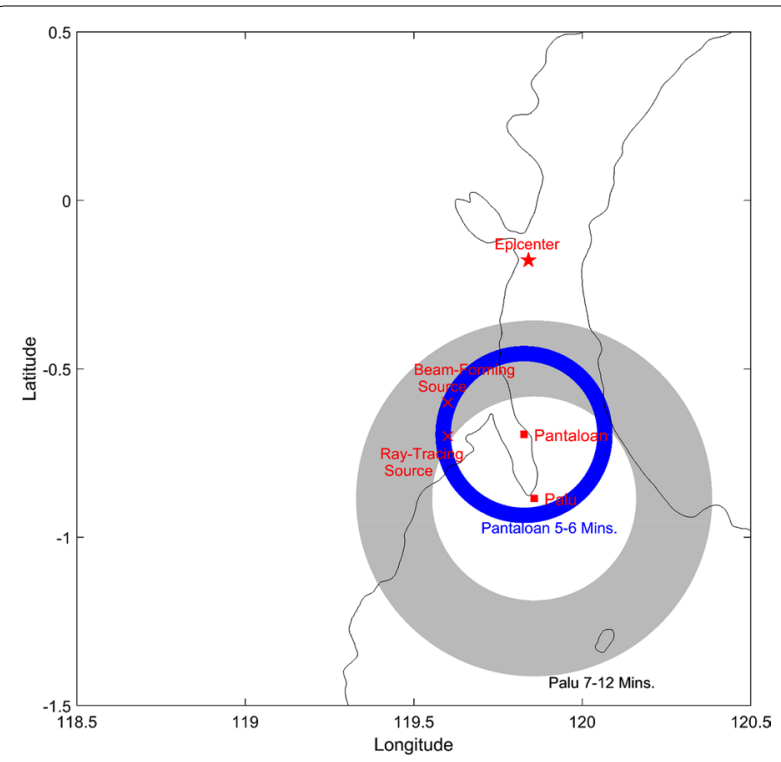

Fig. 3 Validation by using circle method. Blue circle indicates that the possible tsunami source locations centering at Pantoloan-Sulteng tide gauge with radii of the inner edge of $24 \mathrm{~km}(=80 \mathrm{~m} / \mathrm{s} \times 5 \mathrm{~min})$ and the outer edge of $29 \mathrm{~km}(=80 \mathrm{~m} / \mathrm{s} \times 6 \mathrm{~min}) \mathrm{km}$. Gray circle indicates that the possible tsunami source locations centering at the Palu beach area with radii of the inner edge of $34 \mathrm{~km}$ $(=80 \mathrm{~m} / \mathrm{s} \times 7 \mathrm{~min})$ and the outer edge of $58 \mathrm{~km}(=80 \mathrm{~m} / \mathrm{s} \times 12 \mathrm{~min})$ $\mathrm{km}$

the Sulawesi area. It shall be able to drastically shorten the time in detecting TTIDs and confirming a tsunami occurrence, as well as significantly improve the precision in locating the tsunami source, if we make GNSS TEC data derived from existing nearby and/or local ground-based GNSS receivers available in real time. In conclusion, the ionospheric TEC derived from 5 ground-based GNSS receivers in the South Asia region detected 15 TTIDs induced by the 28 September 2018 Sulawesi tsunami and shed some light on the tsunami source location.

\section{Acknowledgements \\ The authors gratefully acknowledge the International GNSS Service (IGS) (ftp://garner.ucsd.edu/) and NASA Crustal Dynamics Data Information System (CDDIS) (ftp://cddis.gsfc.nasa.gov) for providing the ground-based GNSS data.}

\section{Authors' contributions}

All authors read and approved the final manuscript.

\section{Funding}

This study is supported by the Taiwan Ministry of Science and Technology Grant MOST 107-2119-M-008-018. This work was financially supported by the Center for Astronautical Physics and Engineering (CAPE) from the Featured Area Research Center program within the framework of Higher Education Sprout Project by the Ministry of Education (MOE) in Taiwan. 


\section{Availability of data and materials}

The ground-based GNSS observation data were obtained from International GNSS Service (IGS) (ftp://garner.ucsd.edu/) and NASA Crustal Dynamics Data Information System (CDDIS) (ftp://cddis.gsfc.nasa.gov).

\section{Competing interests}

The authors declare that they have no competing interests.

\begin{abstract}
Author details
${ }^{1}$ Center for Astronautical Physics and Engineering, National Central University, Taoyuan, Taiwan. ${ }^{2}$ Department of Space Science and Engineering, National Central University, Taoyuan, Taiwan. ${ }^{3}$ Center for Space and Remote Sensing Research, National Central University, Taoyuan, Taiwan. ${ }^{4}$ Graduate Institute of Statistics, National Central University, Taoyuan, Taiwan. ${ }^{5}$ Graduate Institute of Hydrological and Oceanic Sciences, National Central University, Taoyuan, Taiwan. ${ }^{6}$ Center of Excellence in Earth Systems, Modeling and Observations, Chapman University, Orange, CA, USA. ${ }^{7}$ Graduate School of Science, Chiba University, Chiba, Japan.
\end{abstract}

Received: 11 July 2019 Accepted: 25 July 2020

Published online: 06 August 2020

\section{References}

Aki K, Richards PG (2002) Quantitative seismology. University Science Books, Sausalito

Artru J, Ducic V, Kanamori H, Lognonne P, Murakami M (2005) lonospheric detection of gravity waves induced by tsunamis. Geophy J Int 160:840 848. https://doi.org/10.1111/j.1365-246X.2005.02552.x

Davies K (1990) Ionospheric radio. Peter Peregrinus Ltd, London, p 580

Dean RG, Dalrymple RA (1984) Water wave mechanics for engineers and scientists. Prentice-Hall, Englewood Cliffs

Dias F, Dutykh D (2007) Dynamics of tsunami waves. In: Ibrahimbegovic A, Kozar I (eds) Extreme man-made and natural hazards in dynamics of structures. NATO security through science series. Springer, Dordrecht

Dillon WR, Goldstein M (1984) Multivariate analysis, methods and applications. Wiley, New York, p 163

Efron B, Tibshirani R (1986) Bootstrap methods for standard errors, confidence intervals, and other measures of statistical accuracy. Stat Sci 1(1):54-75

Galvan DA, Komjathy A, Hickey MP, Mannucci AJ (2011) The 2009 Samoa and 2010 Chile tsunamis as observed in the ionosphere using GPS total electron content. J Geophys Res 116:A06318. https://doi.org/10.1029/2010J A016204

Heidarzadeh M, Muhari A, Wijanarto AB (2019) Insights on the source of the 28 September 2018 Sulawesi tsunami, Indonesia based on spectral analyses and numerical simulations. Pure Appl Geophys 176(1):25-43

Hofmann-Wellenhof B, Lichtenegger H, Collins J (1992) GPS theory and practice. Springer, New York, p 326

Huang BS, Chen KC, Yen HY, Yao ZX (1999) Re-examination of the epicenter of the 16 September 1994 Taiwan Strait earthquake using the beamforming method. Terr Atmos Ocean Sci 10:529-542

Jung TK, Liu JY, Tsai HF, Huang BS, Lin CH, Yu SB, Yeh YH (2006) lonospheric disturbances triggered by the Mw7.6 earthquake off the coast of El Salvador on 13 January 2001. Terr Atmos Ocean Sci 17:345-351

Kamogawa M, Orihara Y, Tsurudome C, Tomida Y, Kanaya T, Ikeda D, Gusman AR, Kakinami Y, Liu JY, Toyoda A (2016) A possible space-based tsunami early warning system using observations of the tsunami ionospheric hole. Sci Rep 6:37989. https://doi.org/10.1038/srep37989

Komjathy A, Galvan DA, Stephens P, Butala MD, Akopian V, Wilson B, Verkhoglyadova O, Mannucci AJ, Hickey M (2012) Detecting ionospheric TEC perturbations caused by natural hazards using a global network of GPS receivers: the Tohoku case study. Earth Planet Space 64:24. https://doi. org/10.5047/eps.2012.08.003

Lay T, Wallace TC (1995) Modern global seismology. Academic Press, San Diego, p 512

Lee WHK, Stewart SW (1981) Principles and applications of microearthquake networks. Academic Press, New York, p 293
Liu JY, Tsai HF, Jung TK (1996) Total electron content obtained by using the global positioning system. Terr Atmos Ocean Sci 7(1):107-117

Liu JY, Tsai YB, Ma KF, Chen YI, Tsai HF, Lin CH, Kamogawa M, Lee CP (2006a) Ionospheric GPS total electron content (TEC) disturbances triggered by the 26 December 2004 Indian Ocean tsunami. J Geophys Res 111:A05303. https://doi.org/10.1029/2005JA011200

Liu JY, Tsai YB, Chen SW, Lee CP, Chen YC, Yen HY, Chang WY, Liu C (2006b) Giant ionospheric disturbances excited by the M9.3 Sumatra earthquake of 26 December 2004. Geophys Res Lett 33:L02103. https://doi. org/10.1029/2005gl023963

Liu JY, Tsai HF, Lin CH, Kamogawa M, Chen YI, Lin CH, Huang BS, Yu SB, Yeh $\mathrm{YH}$ (2010) Coseismic ionospheric disturbances triggered by the Chi-Chi earthquake. J Geophys Res 115:A08303. https://doi.org/10.1029/2009J A014943

Liu JY, Chen CH, Lin CH, Tsai HF, Chen CH, Kamogawa M (2011) lonospheric disturbances triggered by the 11 March 2011 M9.0 Tohoku earthquake. J Geophys Res 116:A06319. https://doi.org/10.1029/2011ja016761

Liu JY, Sun YY, Tsai HF, Lin CH (2012) Seismo-traveling ionospheric disturbances triggered by the 12 May 2008 M 8.0 Wenchuan Earthquake. Terr Atmos Ocean Sci 23:9-15. https://doi.org/10.3319/TAO.2011.08.03.01(T)

Liu JY, Chen CH, Sun YY, Chen CH, Tsai HF, Yen HY, Chum J, Lastovicka J, Yang QS, Chen WS, Wen S (2016) The vertical propagation of disturbances triggered by seismic waves of the 11 March 2011 M9.0 Tohoku Earthquake over Taiwan. Geophys Res Lett 43:1-7. https://doi.org/10.1002/2015G L067487

Liu JY, Lin CY, Tsai YL, Liu TC, Hattori K, Sun YY, Wu TR (2019a) lonospheric GNSS total electron content for tsunami warning. J Earthq Tsunami. https://doi. org/10.1142/S1793431119410070

Liu JY, Chen CY, Sun YY, Lee IT, Chum J (2019b) Fluctuations on vertical profiles of the ionospheric electron density perturbed by the March 11, 2011 M9.0 Tohoku earthquake and tsunami. GPS Solut 23:76. https://doi. org/10.1007/s10291-019-0866-7

Murty TS (1977) Seismic sea waves: Tsunamis. Dept. of Fisheries and the Environment, Fisheries and Marine Service, Ottawa

Omira R, Dogan GG, Hidayat R, Husrin S, Prasetya G, Annunziato A, Proietti C, Probst P, Paparo MA, Wronna M, Zaytsev A, Pronin P, Giniyatullin A, Putra PS, Hartanto D, Ginanjar G, Kongko W, Pelinovsky E, Yalciner AC (2019) The September 28th, 2018, Tsunami in Palu-Sulawesi, Indonesia: a post-event field survey. Pure Appl Geophys 176(4):1379-1395

Sardon E, Rius A, Zarraoa N (1994) Estimation of the transmitter and receiver differential biases and the ionospheric total electron content from Global Positioning System observations. Radio Sci 29:577-586

Savastano G, Komjathy A, Verkhoglyadova O, Mazzoni A, Crespi M, Wei Y, Mannucci AJ (2017) Real-time detection of tsunami ionospheric disturbances with a stand-alone GNSS receiver: a preliminary feasibility demonstration. Sci Rep 7:46607. https://doi.org/10.1038/srep46607

Song X, Zhang Y, Shan X, Liu Y, Gong W, Qu C (2019) Geodetic observations of the $2018 \mathrm{Mw} 7.5$ Sulawesi earthquake and its implications for the kinematics of the Palu fault. Geophys Res Lett 46(8):4212-4220

Sun YY, Liu JY, Lin CY, Tsai HF, Chang LC, Chen CY, Chen CH (2016) lonospheric F2 region perturbed by the 25 April 2015 Nepal earthquake. J Geophys Res Space Phys 121:5778-5784. https://doi.org/10.1002/2015JA022280

Tsai HF, Liu JY, Lin CH, Chen CH (2011) Tracking the epicenter and the tsunami source with GPS ionosphere observation. Earth Planet Space 63:63. https ://doi.org/10.5047/eps.2011.06.024

Wu SL (1992) Electron density profiles in Taiwan. MS thesis, National Central University, Taiwan, pp 83

\section{Publisher's Note}

Springer Nature remains neutral with regard to jurisdictional claims in published maps and institutional affiliations. 